\title{
MEDIAÇÕES E REPRESENTAÇÕES EM CONFLITO NA LUTA PELATERRA ENTRE INDÍGENAS E AGRICULTORES NO NORTE DO RIO GRANDE DO SUL, BRASIL
}

\author{
Henrique Aniceto Kujawa* \\ João Carlos Tedesco
}

\begin{abstract}
Resumo
Na última década, na região norte do Rio Grande do Sul, constituíram-se dezenas de reivindicações de novas terras indígenas em locais de colonização centenária de agricultores familiares. Os conflitos decorrentes deste contexto extrapolam o binômio, historicamente constituído, da luta entre latifúndio/agronegócio versus sem-terra/pequenos agricultores e, consequentemente, provocando a reconfiguração da atuação dos movimentos sociais do campo, principalmente a Federação Nacional dos Trabalhadores e Trabalhadoras na Agricultura Familiar (Fetraf) que, historicamente, se articulavam ideológica e programaticamente com as causas indigenistas, entidades e movimentos que as representavam. Movimentos que, historicamente, se encontravam no mesmo campo de luta, agora se veem em campos distintos. $\mathrm{O}$ presente artigo, utilizando fontes documentais, bibliografias e entrevistas, analisa os dilemas enfrentados por estes sujeitos, a forma como reformulam suas práticas discursivas e reconfiguram suas atuações junto a suas bases e no conjunto da sociedade para melhor se adaptar a essa nova realidade.
\end{abstract}

Palavras-chave: Conflitos Sociais. Indígenas. Agricultores Familiares. Políticas públicas.

\footnotetext{
* Doutor em Ciências Sociais pela Universidade do Vale do Rio dos Sinos (UNISINOS), professor da Faculdade Meridional (IMED) - Passo Fundo.E-mail: kujawa@imed.edu.br

** Doutor em Ciências Sociais pela Universidade Estadual de Campinas (Unicamp). Professor do Programa de Pós-Graduação em História da Universidade de Passo Fundo (PPGH/UPF). E-mail: jctedesco@upf.br
} 


\section{Introdução}

O conflito pela terra envolvendo indígenas e agricultores no Centro-Norte do Rio Grande do Sul já ganhou dimensão estruturante. Já são quase duas décadas de intensos confrontos, múltiplos grupos diretamente envolvidos e outros tantos correlacionados.

A proposta de constituição de Terras Indígenas em locais ocupados, centenariamente, por agricultores familiares criou mudanças na configuração dos campos de disputa ideológica que, tradicionalmente, posicionavam-se: de um lado, os defensores dos interesses das pequenas propriedades, dos agricultores familiares, dos sem-terra, dos indígenas e quilombolas e, do outro lado, o latifúndio improdutivo e o agronegócio.

A nova configuração reposicionou, genericamente, os movimentos entre os defensores da criação de Terras Indígenas e os defensores da legitimidade dos agricultores permanecerem em suas comunidades e propriedades. Colocam-se, dessa forma, em campos opostos, movimentos que historicamente tinham atuação articulada e, simultaneamente, aproximam-se outros que atuavam em sentidos opostos.

Nesse horizonte de disputas, há o universo de interpretação histórica sobre o passado, em particular, de fatos históricos em torno de políticas públicas, colonização, intrusão, esbulho e apropriação da terra, centradas no papel do Estado, bem como da legalidade e legitimidade da apropriação da terra, dos significados da terra para os grupos sociais envolvidos.

No cenário dos embates explicativos e de tomadas de posições, há concepções de desenvolvimento, de identidade e de cultura. No campo das mediações e organizações sociais afins (sindicatos, federações etc.), há múltiplas polêmicas, adesões e vinculações até então inexistentes, bem como distanciamentos em razão da pauta em questão.

$\mathrm{O}$ referido conflito adentra com intensidade nos campos político e jurídico; nesses dois universos de saber e de decisão, há ambiguidades, diferenciações e tomadas de 
posições muito antagônicas e que revelam a complexidade do tema e a dificuldade de encontrar caminhos alternativos e que não sejam de opostos na esfera da inclusão/exclusão.

As disputas e polêmicas apresentam-se em horizontes institucionais, como é o caso da Igreja Católica, do Instituto Nacional de Colonização e Reforma Agrária (Incra), da Fundação Nacional do Índio (Funai), da Federação dos Trabalhadores na Agricultura Familiar (Fetraf), da Federação da Agricultura do Rio Grande do Sul (Farsul), entre outros. Múltiplos profissionais de áreas inter e multidisciplinares, legitimados por instituições de ensino superior, também estão envolvidos, principalmente nas elaborações de laudos técnicos para ambos os grupos, com interpretações históricas, narrativas de memórias oral, busca de vestígios, análises documentais, recursos imagéticos, enfim, um amplo acervo de fontes para permitir o melhor argumento, a sensibilização em torno da demanda, as justificativas plausíveis, a demonstração do passado histórico envolvendo os sujeitos sociais em questão.

Há embates entre instâncias do próprio Estado, principalmente entre o Incra e a Funai, no interior de dioceses do Centro-Norte do Rio Grande do Sul, palco dos conflitos em questão, em particular na instância de Passo Fundo e de Vacaria nas suas concepções frente às ações do Conselho Indigenista Missionário (CIMI), entidade da Igreja Católica que atua e defende a causa indígena.

Concepções sobre identidades indígenas do século XXI, desenvolvimento econômico e preservação ambiental também movimentam mediações e representações de grupos sociais; algumas instituições, nesse sentido, emitem seu parecer em torno da luta entre os grupos sociais envolvidos em razão de suas percepções sobre esses temas.

Como há muitos elementos envolvidos no processo para além dos dois sujeitos sociais em questão, optamos, neste texto, por um recorte analítico e daremos ênfase a questões que centralizam o papel e as posições da Fetraf, pois essa é uma entidade de grande expressão na Região Norte do Rio Grande 
do Sul e que possui, em sua história, um vínculo orgânico com os agricultores familiares.

O que buscamos ver é que, diante da ameaça sofrida pela sua base (os pequenos agricultores) de perder as terras, a entidade, como, aparentemente, não podia deixar de ser, assume uma posição em favor dos agricultores, aproximandose de movimentos de defesa da propriedade como a Farsul, entidade expressiva e de representação do latifúndio agrícola e pastoril. Com isso, a Fetraf distanciou-se de parceiros históricos como a Comissão Pastoral da Terra (CPT), o CIMI, os Movimentos dos Pequenos Agricultores (MPA) e o Movimento dos Trabalhadores Rurais Sem-Terra (MST), que possuem uma posição favorável à constituição das novas terras indígenas.

Uma segunda mudança, fruto deste contexto, é a relação dos movimentos sociais do campo, principalmente a Fetraf, com o Estado e com os atuais governos. Uma relação que, na última década, era de reconhecimento mútuo, da consolidação de políticas afirmativas (lei de reconhecimento do agricultor familiar, financiamento subsidiado à produção, compra de maquinário, construção de casas, entre outros), passou por um processo de enfrentamento.

Desse modo, buscamos analisar o fato de que o Estado, na política de demarcação de terras indígenas, não reconhecia a diferença do agricultor familiar e do latifúndio. A Fetraf, por sua vez, precisou desenvolver estratégias, incluindo negociações e mobilizações, para ser reconhecida como representante dos agricultores potencialmente atingidos pelas demarcações e, posteriormente, criar uma nova pauta na efetivação da política territorial indígena que reconhecesse a especificidade das regiões de colonização histórica.

Enfim, mesmo nesse específico recorte que fizemos, há um amplo debate, confrontos e tensões para além dos sujeitos coletivos diretamente envolvidos, fato esse que revela uma realidade complexa, de grande envolvimento social, político, histórico e cultural, a qual se condensa na disputa pelo mesmo espaço por dois grupos sociais. Nesse sentido, de uma forma 
sintética, mais informativa do que analítica, utilizamos revisão bibliográfica, documentos internos e entrevistas com dirigentes ${ }^{1}$ da referida entidade e materiais de imprensa.

\section{Um conflito de múltiplas dimensões}

Os conflitos que estamos vivendo, nessa última década, possuem raízes e reproduzem muitas das características históricas, mas possuem algumas especificidades, dentre elas destacamos a conquista indígena do direito étnico, cultural e territorial na Constituição de 1988 suplantando formalmente a lógica assimilacionista. Por outro lado, as terras que estão sendo reivindicadas pelos indígenas na última década estão em regiões como maior densidade demográfica, atingindo, principalmente, no oeste do Paraná e Santa Catarina e no norte do Rio Grande do Sul, locais colonizados pelo Estado e ocupados pelos imigrantes e seus descendentes.

$\mathrm{Na}$ Região Sul, na última década, a reivindicação indígena por demarcação de terras que foram vendidas e escrituradas pelo Estado aos agricultores, em alguns casos, há mais de um século, hoje se caracterizam como áreas de agricultura familiar. Em um raio de duzentos quilômetros de Passo Fundo, constituíram-se em torno de duas dezenas de pontos de conflitos territoriais, em sua grande maioria, com acampamentos indígenas em beira de rodovias, terras públicas ou de agricultores e com processos administrativos de Identificação, Delimitação e Demarcação de Terra Indígena tramitando na Funai.
1 Foram entrevistados três dirigentes da Federação: Sidimar Lavandoski (presidente do Sindicato da Agricultura Familiar de Sananduva e dirigente da Fetraf do Rio Grande do Sul), Rui Valença (presidente da FetrafSul) e Celso Ludwig (dirigente da Fetraf-Santa Catarina, da Fetraf-Sul e da Fetraf-Brasil). As entrevistas seguiram um modelo semiestruturado, gravadas em vídeo e áudio. Foram feitas quatro entrevistas, uma com o Sidimar em 2013, outras três com o Celso, Sidimar e Rui em 2015. O roteiro das entrevistas buscou informações sobre a compreensão e o posicionamento da Fetraf frente às disputas territoriais; possíveis tensões entre a posição da Fetraf e sua base; a relação estabelecida com outros movimentos sociais, governo e partidos políticos; possíveis soluções para as disputas territoriais. As entrevistas foram presididas da assinatura do Termo de Consentimento Livre e Esclarecido. Neste texto, as citações das entrevistas serão enumeradas como entrevistado 1, 2, 3 e 4, não havendo a identificação das pessoas. 
Mapa 1 - Conflitos de luta pela terra no norte do RS

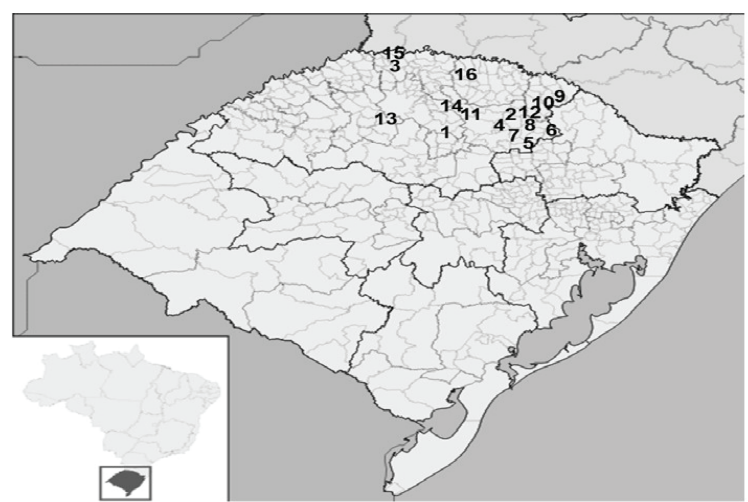

1.Carazinho - Indígenas 2.Sertão - Quilombolas

3. Frederico Westphalen - Indígenas

4.Coxilha - Quilombolas

5.Gentil-Indígenas

6. Caseiros - Indígenas

7. Mato Castelhano - Indígenas

8. Água Santa - Indígenas

9. Cacique Doble - Indígenas

10.Sananduva - Indígenas

11. Getúlio Vargas - Indígenas

12. Faxinalzinho - Indígenas

13. Novo Xingu/Constantina - Indígenas

14.Pontão - Indígenas

15.Vicente Dutra - Indígenas

16. Benjamin Constant do Sul - Indígenas

Fonte: Elaborado pelo autor com base em pesquisa de campo.

2 Embora constituídas formalmente pelo Estado, as aldeias não possuíam um território demarcado, sendo que seus limites e sua população oscilava de acordo com os interesses territoriais e com conflitos internos entre indígenas que provocavam mobilidade e reagrupamento.
Nos primeiros séculos da colonização, as políticas indigenistas não repercutiam muito na Região Sul, pois a centralidade da atividade econômica da colônia se desenvolvia no litoral nordestino. Temos, na região em tela, a constituição das primeiras Reduções Jesuíticas Espanholas, destruídas pelos bandeirantes no século XVII e depois a constituição dos Sete Povos das Missões. Contudo, no final do século XVIII e no século XIX, os contatos e conflitos com os povos indígenas kaingang se intensificaram motivados pelo crescimento das atividades tropeiras, pela necessidade de constituição de novos caminhos que ligassem os campos do Sul com São Paulo e, mais tarde, pela política de colonização objetivando consolidar o domínio político e econômico sobre este território (BECKER, 1995).

$\mathrm{O}$ processo de aldeamento, intensificado a partir de 1840, voltou a contar com a participação de missionários e objetivava aglutinar os indígenas em territórios específicos, sob a tutela da igreja e do Estado, para garantir que eles não representassem ameaças aos tropeiros, aos estancieiros e ao processo de colonização que estava avançando pelo território sul-rio-grandense. Nesse período foram constituídas as aldeias de Nonoai, Guarita e Campo do Meio $^{2}$ (LAROQUE, 2000). 
OEstado Republicano trouxeconsigoo debate positivista de constituição de um estado laico e da compreensão de que as comunidades indígenas precisavam ser assistidas por políticas estatais garantindo que o seu processo de evolução humana ocorresse de forma gradual e espontânea. Simultaneamente, intensificou-se a colonização na Região Norte do estado para abrigar imigrantes e, principalmente, descendentes de imigrantes, cujas famílias tinham ocupado a região serrana, que buscavam novas terras para se estabelecerem. Foi dessa forma que o governo do Rio Grande do Sul, por meio da Divisão de Terras e Colonização, liderada pelo Engenheiro Carlos Torres Gonçalves, demarcou, entre 1910 e 1918, 11 áreas indígenas, conhecidas como toldos. A demarcação dos toldos, por um lado, estabeleceu oficialmente, no intuito de proteger o território indígena; por outro, restringiu enormemente os espaços que as comunidades tribais utilizavam para circulação, caça, pesca e coleta, declarando-as como "terras devolutas" e, portanto, passíveis de destinação para loteamento e venda aos imigrantes.

O Rio Grande do Sul, até 1940, diferentemente dos demais estados onde a política territorial indigenista era coordenada pela união através do Serviço de Proteção do Índio (SPI), administrou os toldos, mas não garantiu, na prática, o respeito aos seus limites, tampouco que eles estivessem a serviço do desenvolvimento cultural de suas comunidades. A concepção de que os toldos deveriam ser economicamente autossustentáveis e de que os indígenas deveriam, gradualmente, transformar-se em agricultores, fez com que se desenvolvessem práticas de cultivo das terras com a mão de obra das referidas comunidades, coordenadas pela administração dos toldos ${ }^{3}$. Para além disso, desenvolveram-se formas de exploração das riquezas dos toldos pela extração da madeira, principalmente a araucária, e com o cultivo das terras por meio do arrendamento ou do arranchamento. A CPI do Índio, instaurada na Assembleia Legislativa Gaúcha (1967), para apurar os conflitos em terras indígenas na região de Nonoai, sistematiza, com fartura de documentação e
3 O trabalho dos indígenas ficou conhecido como panelaço pelo fato de todos trabalharem em troca de comida servida em grandes panelas. Essa prática está relatada com detalhes por entrevistados indígenas hoje moradores no acampamento do Passo Grande do Forquilha (VEIGA, 2005). 
relatos, licitações feitas para a venda e retirada de madeira que objetivavam arrecadar dinheiro para garantir o autossustento financeiro, mas que, na prática, legitimavam a retirada indiscriminada da referida riqueza, ou seja, muito além das quantias licitadas (RIO GRANDE DO SUL, 1968;

4 A diferença de arrendamento era feita por intermédio de contratos firmados com a administração do Toldo, inclusive com a cobrança de imposto territorial feito pelo Instituto Gaúcho de Reforma Agrária (IGRA) (KUJAWA, 2014).

5 No Oeste de Santa Catarina, o processo de ocupação foi conduzido pelas Companhias Colonizadoras que ganhavam a concessão da terra do Estado, retiravam a madeira de maior valor comercial e depois as vendiam para imigrantes europeus ou descendentes de imigrantes que partiam do Rio Grande do Sul avançando a fronteira agrícola. Esse processo também restringiu o território indígena em detrimento dos processos de colonização (WERLANG, 2006; NACKE; BLOEMER, 2007).

6 Os toldos extintos foram o de Serrinha, Ventarra e Caseros; dos demais, o único que não teve a área reduzida foi Ligeiro (CARINI, 2005).

7 O governo do Rio Grande do Sul constituiu um grupo de trabalho que fez um estudo, resultando em um relatório que definiu com precisão as terras indígenas que tinham sido reduzidas e as respectivas áreas (RIO GRANDE DO SUL, 1997).
KUJAWA, 2015). O mesmo ocorre com as terras que eram arrendadas oficialmente, por intermédio de contratos, para quem quisesse cultivá-las e pagar a taxa de $20 \%$ pelo uso da terra. Junto com os contratos de arrendamento, desenvolvese o arranchamento ${ }^{4}$ de centenas de famílias de descendentes de imigrantes que avançavam a fronteira agrícola e buscavam novas possibilidades de sobrevivência. ${ }^{5}$

O resultado do processo descrito foi uma redução drástica, entre as décadas de 1940-1960, das terras indígenas demarcadas, reduzindo alguns toldos e extinguindo outros ${ }^{6}$, destinando as terras para a constituição de reservas florestais ou para o loteamento e assentamento de agricultores. Embora a CPI do Índio da Assembleia Legislativa do Rio Grande do Sul tenha considerado ilegal a venda de terras historicamente demarcadas como de indígenas, os conflitos entre esses e os agricultores tenha se intensificado no final da década de 1970, foi apenas na década de 1990 que o estado sul-riograndense reconhece a ilegalidade de seus atos e inicia o reestabelecimento dos limites históricos dos toldos. A referida mudança da postura do estado está vinculada, por um lado, ao avanço e à legitimação do direito territorial indígena conquistado na Constituição de 1988 (art. 231 e 232) e, na sequência, na Constituição do Rio Grande do Sul, que, no seu art. 32, reconhece que o estado deveria restituir as terras indígenas e indenizar os agricultores nelas assentados. ${ }^{7}$

Destaca-se que a retirada de centenas de famílias de agricultores que haviam comprado terras do estado (19401960) e o estabelecimento de limites originais dos toldos indígenas foi traumática para os dois grupos sociais envolvidos. Os agricultores que, após décadas de vínculos econômicos, sociais e culturais, viram-se obrigados a reconhecer que foram enganados pelo Estado e buscar novos locais para 
continuar suas vidas, e muitos deles até hoje não receberam a indenização devida. ${ }^{8}$ Para os indígenas que voltaram para suas terras, mas que, após décadas de cultivo agrícola intensivo, não as encontraram nas condições de outrora, tampouco em condições de satisfazer as necessidades vividas pelas suas comunidades que há décadas viviam em pequenas áreas ou nas pequenas cidades da região sem condições de produzir o próprio sustento, integrando-se, mesmo que subalternamente, à lógica do mercado.

Portanto, os conflitos vividos, na região em tela, na última década, têm, de um lado, os indígenas que reivindicam a demarcação de terras consideradas por eles de ocupação tradicional, mas que os impediu de permanecer nelas com a demarcação dos toldos (1910-1918), de outro lado, os agricultores, descendentes dos imigrantes que chegaram à região na mesma época, compraram as terras do Estado e, há um século, constituíram e mantêm vínculos com a mesma.

É nesse contexto que as entidades que historicamente possuíam identidade ideológica e pautavam na defesa dos agricultores familiares, os sem-terra e os indígenas, em contraposição ao latifúndio e ao agronegócio, deparam-se com uma reconfiguração das pautas diante das atuais políticas territoriais ao proporem a demarcação de terras em locais de ocupação da agricultura familiar.

\section{Mediações, vinculações e ambiguidades: a tomada de posição da Fetraf-Sul}

A Fetraf-Sul surge do contexto (final da década de 1980 e 1990) do movimento sindical rural, vinculado à Central Única dos Trabalhadores (CUT), que se contrapunha à estrutura sindical oficial e da consolidação do conceito de agricultura familiar por meio de reflexões acadêmicas e de políticas públicas.

Ainda no processo de redemocratização e de articulação do movimento sindical com os diferentes movimentos sociais surge, em 1984, por iniciativa do Movimento Sem-Terra (MST), do Movimento dos Atingidos por Barragem (MAB), 
9 A Fetraf-Brasil/CUT está organizada em 18 estados, com mais de 600 sindicatos e associações sindicais em mais de mil municípios em todo o Brasil, com aproximadamente 500 mil agricultoras e agricultores associados (FETRAFBRASIL/CUT, [s. d.]).

10 Picolotto (2014, p. 217), ao tratar deste tema, ressalta que o termo "[...] trabalhador aponta seu posicionamento ao lado das organizações de trabalhadores no universo sindical e a sua oposição às organizações patronais do campo [...]. Trata-se de uma opção ideológica coerente com sua trajetória anterior. Em segundo lugar, o uso do termo 'trabalhadores' pretendia reforçar sua vinculação com a CUT (e com o PT), como central de trabalhadores". do Movimento de Mulheres Trabalhadoras Rurais (MMTR) e setores da Igreja Católica, uma articulação de oposição sindical no campo que se contrapunha ao modelo sindical assistencialista representado pelos sindicatos de trabalhadores rurais (STRs) e da Federação deTrabalhadores Rurais (FETAG), conhecida como Articulação Sul. Alguns anos depois (1988), a CUT constituiria os Departamentos dos Trabalhadores Rurais (DETRs) em diversos estados e, em nível nacional, o DNTR. Durante a década de 1990, esse setor sindical utilizou diferentes estratégias com o intuito de fortalecer-se passando pela disputa das estruturas sindicais oficiais (FETAGs e CONTAG), filiando-as à CUT até que, em 2001, houve uma opção de constituir uma estrutura sindical paralela com a constituição da Fetraf-Sul. Em 2004, ocorreu o primeiro Encontro Nacional da Agricultura Familiar que fundou a Federação Nacional dos Trabalhadores e Trabalhadoras na Agricultura Familiar (FETRAF-BRASIL/CUT) ${ }^{9}$.

A partir da década de 1990 desenvolveram-se políticas públicas específicas, como o Programa Nacional de Fortalecimento da Agricultura Familiar (1995), e constituíram-se espaços governamentais específicos para dialogar com este público, como a Secretaria da Agricultura Familiar, vinculada ao Ministério do Desenvolvimento Agrário (2003), culminando com a criação de uma Lei da Agricultura Familiar - Lei no 11.326, de 24 de julho de 2006 (BRASIL, 2006), que positiva a compreensão e caracterização dos Agricultores Familiares, reconhecendo-os como profissão e regulamentando o direito de acesso a políticas públicas e de financiamento específicos. ${ }^{10}$

O posicionamento ideológico da entidade também fica evidente no documento da fundação da Fetraf-Sul (2001) quando aponta que o seu objetivo central é ser "[...] uma organização diferenciada das outras organizações do campo, articulando a luta política de forma integrada (visão global) com a organização econômica/social, construindo caminhos e alternativas concretas para os agricultores e agricultoras familiares". 
É recorrente na documentação institucional da referida federação a preocupação de demonstrar a sua vinculação, simultaneamente, com proposta de melhoria de vida dos agricultores familiares e com a construção de um modelo de sociedade e desenvolvimento sustentável e solidário ${ }^{11}$. Nesse sentido, coloca-se como tarefa central a capacidade de organização, mobilização e negociação com o Estado para construir políticas públicas capazes de viabilizar a agricultura familiar e uma sociedade que prima pela sustentabilidade e por práticas públicas redistributivas, claramente propondo-se a ser protagonista de um projeto caracterizado historicamente como sendo de esquerda, somando-se a CUT e articulado estrategicamente com o Partido dos Trabalhadores (PT) e as pastorais sociais da Igreja Católica na construção de um campo político-ideológico. ${ }^{12}$ Desse modo, a Federação e seus sindicatos articularam-se com um campo político, juntamente com a CUT, com outras organizações do meio rural como o Movimento Sem-Terra, com pastorais sociais e setores da Igreja Católica vinculados à Teologia da Libertação e o PT para se contrapor ao modelo de desenvolvimento com base no latifúndio e defender a permanência dos agricultores familiares em suas terras e para a ampliação de políticas públicas que melhorassem suas condições econômicas e sociais.

Os conflitos territoriais envoltos na restituição de áreas historicamente demarcadas e/ou a criação de novas Terras Indígenas em regiões tipicamente de agricultura familiar passa, nas últimas décadas, por dois momentos distintos. O primeiro, na década de 1990, no Rio Grande do Sul, quando este estado, a partir do novo marco constitucional, reconheceu ter vendido indevidamente áreas indígenas para agricultores, se propôs a indenizar ou reassentar as famílias dos agricultores e restituir o território indígena. Neste caso, por mais que os agricultores estivessem sendo penalizados com a necessidade de abandonar o território que há décadas se constituíra no lócus econômico, social e cultural, não havia o que fazer, pois efetivamente o Estado tinha vendido para agricultores terras que pertenciam aos toldos indígenas demarcados no início do
11 Os objetivos principais da Fetraf-Brasil/CUT são: "Fortalecer e ampliar a representação dos agricultores e agricultoras familiares do Brasil; Unificar a ação sindical cutista, tendo como eixo central o fortalecimento da agricultura familiar; Construir um projeto de desenvolvimento Sustentável e Solidário" (FETRAFBRASIL/CUT, [s. d.]).

12 Do ponto de vista da estrutura organizativa, a Fetraf rompe com base municipal, organizando sindicatos regionais; na região Sul, conta com 93 sindicatos abrangendo 288 municípios. Do ponto de vista da estratégia de atuação, reforça o trabalho de base e as mobilizações (jornadas de luta) para constituição de políticas públicas que favoreçam os agricultores familiares. 
século $\mathrm{XX}$. O segundo, intensificado na última década, com a reivindicação para a criação de terras indígenas em locais colonizados no norte do Rio Grande do Sul, oeste de Santa Catarina e Paraná. O número de processos administrativos e de acampamentos se multiplica, e a maioria deles ameaça terras de agricultores familiares que as compraram nas primeiras décadas do século XX.

Do ponto de vista interno da Federação e dos sindicatos a ela vinculados, aparentemente, parece-nos evidente que a referida tivesse um posicionamento imediato e unânime em defesa das propriedades dos agricultores; contudo, a complexidade da realidade específica coloca, de um lado, a sua base social, agricultores familiares, que estão ameaçados e, de outro, indígenas e entidades indigenistas, notadamente o CIMI, o qual se encontra no mesmo campo de articulação ideológica. Do ponto de vista programático, a Fetrafidentificase e é identificada pela base e pela sociedade como defensora do direito territorial indígena. Isso gerou, de imediato, certa desconfiança da base quanto ao efetivo posicionamento dos seus sindicatos e também dificuldades das instâncias da Federação e da CUT, mais distantes dos problemas vivido pelos agricultores específicos, compreender o que estava efetivamente ocorrendo.

Este é um tema de difícil compreensão entre as próprias lideranças que historicamente defendem uma causa em que os índios estão dentro dela, ou seja, defender os mais pobres, aqueles que sempre foram excluídos da sociedade. [...] isso foi muito difícil de compreender dentro da FETRAF, ou seja, de como a FETRAF iria ter uma posição contrária daquilo que os índios estavam reivindicando. (Entrevistado 1).

As dificuldades também eram encontradas na relação com a base do sindicato. Em casos específicos de municípios onde os conflitos estão localizados, as lideranças várias vezes tiveram de responder à acusação de que o sindicato teria sido apoiador do movimento indígena em função de ter sido um dos promotores (juntamente com a CPT, CIMI e Pastoral da 
Terra) da Romaria da Terra que abordava o tema. Na prática, este argumento foi largamente utilizado para deslegitimar o sindicato, mas não repercutiu na base na medida em que a atuação do sindicato, suas propostas e seu discurso, sempre incluiu a defesa dos direitos dos agricultores e indígenas. ${ }^{13}$

Segundo os dirigentes entrevistados, a superação dessas dificuldades passou por dois movimentos. O primeiro foi uma melhor compreensão do novo contexto dos conflitos territoriais que estão colocando em disputa indígenas e agricultores, análise da história das políticas indigenistas, percepção de que o que estava se questionando não é o direito dos índios, mas sim a política indigenista, que está propondo a criação de novas terras indígenas em locais habitados centenariamente por agricultores familiares. A história das regiões de colonização no norte do Rio Grande do Sul, Oeste de Santa Catarina e Paraná, possuem especificidades em relação a outras regiões do Brasil, os agricultores não grilaram/usurparam terras indígenas, mas as compraram do Estado. Portanto, a posição da Fetraf não deixou de defender o direito indígena, mas sim questionar a política indigenista que nega a história dos agricultores familiares e a consciência que o problema vivido na atualidade foi criado pelo Estado brasileiro.

Este é um problema que o Estado brasileiro criou, que há mais de 100 anos colonizou, trazendo imigrantes da Europa [...] e colocou em áreas que já eram ocupadas, que tinham comunidades indígenas [...], portanto temos que resolver este problema, mas tem um responsável que se chama Estado Brasileiro. Portanto, nós temos muito claro que a nossa luta não é pela supressão do direito indígena em detrimento do nosso direito. [...] temos a compreensão que somos duas vítimas do processo histórico desenvolvido no nosso país. (Entrevistado 4).

O segundo movimento foi a intensificação de esclarecimento da base e das diferentes instâncias da Federação. Em relação à base, foram feitas diversas reuniões com lideranças e rodadas de assembleias nas comunidades para discutir o tema e esclarecer a posição assumida pelo Sindicato.
13 Os relatos dos dirigentes entrevistados apontam que nos últimos anos a Fetraf formulou e amadureceu o seu posicionamento e hoje "[...] tem clareza que é necessário construir uma nova política pública com as seguintes bases: os agricultores reconheçam publicamente o direito indígena, mas também os indígenas $\mathrm{e}$ as entidades que defendem os direitos indígenas precisam reconhecer o direito dos agricultores a terra, especialmente estes agricultores familiares que compram a terra do Estado e vivem nela muitas vezes há mais de 100 anos" (Entrevistado 2). 
Em relação às instâncias da Fetraf, foram feitas reuniões, seminários temáticos, produzindo documentos que sistematizavam as reflexões feitas e, segundo dirigentes, estão conseguindo ampliar a compreensão e conquistando a adesão

[...] aqui no Rio Grande do Sul este debate dentro da CUT está evoluindo bem, com muitas crises, mas é um debate que está conseguindo avançar, inclusive a CUT conseguiu no estado do Rio Grande do Sul elaborar documentos públicos colocando sua posição diante das questões que estão acontecendo. [...] assim como na FETRAF Brasil, então esse debate dentro da central sindical a nível nacional precisa de muito esforço para ser feito. (Entrevistado 3).

Percebe-se, mesmo com as dificuldades relatadas, que a Fetraf - principalmente, as lideranças dos sindicatos onde os conflitos estão ocorrendo - está conseguindo produzir o convencimento de que a defesa do direito à propriedade dos agricultores familiares não significa ser contrário à cultura e ao direito indígena. Corrobora com esta afirmação a nota pública da CUT/RS que explicita a posição de defesa dos agricultores, sem, com isso, negar a necessidade de políticas públicas que garantam o direito indígena.

Os conflitos de terras que envolvem agricultores familiares, comunidades quilombolas e povos indígenas possuem certas especificidades na região sul. Diferente de outras regiões do país onde os latifundiários e os agentes do agronegócio avançam na propriedade e acionam dispositivos de violência e extermino de populações tradicionais, na região sul o grande desafio é encontrarmos soluções pactuadas que preservem direitos adquiridos pelos agricultores familiares e assegurem a sobrevivência física e cultural dos povos indígenas e quilombolas. (CUT, 2013, [s. p.]).

A mesma posição está explicitada na resolução na décima quarta Plenária Estadual da CUT, realizada em maio de 2014, o que demonstra a consolidação do posicionamento da referida Central. 
As dificuldades enfrentadas internamente na Fetraf e na CUT aumentam significativamente quando analisamos a relação com os demais movimentos sociais e entidades. Por um lado, a defesa dos direitos dos agricultores aproximou os sindicatos de outras entidades, inclusive da Federação da Agricultura do Rio Grande do Sul (Farsul), vinculada aos empregadores rurais e ao agronegócio. Diante da complexidade vivida pelos agricultores, da dificuldade de dialogar com as instituições do Estado (principalmente Ministério Público Federal e Funai), da pluralidade de organizações que se colocaram ao lado dos agricultores, houve a necessidade de unificar as ações específicas ainda que houvesse divergências ideológicas. Nos municípios onde estão ocorrendo os conflitos esse processo foi facilitado pela proximidade e vivência cotidiana, as quais escondiam possíveis divergências. Nos diferentes locais foram criadas associações de defesa dos agricultores e comissões que agregavam, para além dos agricultores atingidos, lideranças e entidades municipais. ${ }^{14}$

Contudo, nas relações mais amplas, a posição dos sindicatos e da Fetraf-Sul foi duramente questionada seja no sentido de, supostamente, colocarem-se contrários ao direito indígena e, principalmente, de desenvolver ações conjuntamente com a Farsul e outras entidades ligadas ao agronegócio. $\mathrm{O}$ exemplo mais emblemático e contundente deste questionamento foi expresso pelo CIMI em documento público fazendo críticas à atuação do governador do Rio Grande do Sul, Tarso Genro e comparando a Fetraf à Farsul.

É incrível como o Governo do Estado, hoje gestado por um partido que se diz dos trabalhadores, de aliança histórica com os oprimidos do campo, consegue (ou ao menos pensa que consegue) insistir em travestir os setores conservadores da FARSUL e da FETRAF-Sul (que já são quase a mesma coisa) de pequenos agricultores e garantir a estes, os inimigos dos verdadeiros pequenos (indigenas, quilombolas e, sobretudo campesinos) a legitimidade de tratar desta problemática que há muito os interessa. (CIMI, 2013, [s. p.], grifo no original). ${ }^{15}$
14 Questionado sobre a relação do sindicato com as demais entidades e possíveis conflitos, o dirigente assim se expressa: "No local, a gente tem definido uma questão estratégica que é quando faz as ações, chama junto, então o pessoal vem sempre. São muito difíceis ações locais que o sindicato da agricultura familiar faz sozinho, ou seja, quando a ação envolve esse tema vem todos e toda a comissão pensa junto, mesmo que seja uma mobilização a nível estadual, em nível do Sul do Brasil, seja construída somente pela Fetraf; aqui no local nós chamamos todos" (Entrevistado 1).

$15 \mathrm{O}$ documento conclui afirmando que: "Estão sendo considerados inimigos dos povos indígenas em nível estadual: $\mathrm{O}$ governador Tarso Genro; o assessor do Governador e representante da Consulta Popular, Milton Viário; o secretário dos Direitos Humanos, Fabiano Pereira; o secretário de Desenvolvimento Rural, Pesca e Cooperativismo (SDR), Ivar Pavan; o chefe de Gabinete da SDR, Inácio Benincá; o diretor geral da SDR, Elton Scapini; os setores conservadores da Fetraf-Sul e da Farsul' (CIMI, p. 2-13, grifo dos autores). 
O posicionamento deste documento é, por várias vezes, reiterado publicamente, demonstrando que entidades historicamente parceiras da Fetraf-Sul passam a questionar um dos elementos centrais de sua identidade política, qual seja a compreensão de que a efetivação do direito dos agricultores familiares passa por um modelo de desenvolvimento que inclua os diferentes setores sociais historicamente excluídos.

$\mathrm{Na}$ avaliação dos dirigentes, apesar da dificuldade de dialogar especificamente com o CIMI, foram feitos debates com os setores da Igreja Católica envolvendo bispos de dioceses e com a própria Conferência Nacional dos Bispos Brasileiros resultando em uma melhor compreensão da posição da Fetraf. Nas dioceses da região norte do Rio Grande do Sul, região de maior intensidade do conflito, houve manifestações públicas de bispos que demonstraram a preocupação com a complexidade do contexto e reconheceram que os índios têm direito a uma vida digna, mas que os agricultores também possuem direito sobre estas terras que compraram do Estado. Os bispos da diocese de Vacaria emitem uma Declaração explicitando o direito de os agricultores da região pretendida pela TI Passo

$16 \mathrm{Em}$ face às "[...] tensões provocadas por disputas de terras, entre colonos e índios, em nossa área de atuação, a diocese de Vacaria vem publicamente manifestar-se que não reconhece a existência de nenhuma área Indígena no território situado entre: leste, Rio Inhandava (Forquilha) e o Rio Apuaê (Ligeiro) e nortesul, rio Pelotas e BR 285. Com esta nossa Declaração, esperamos contribuir no sentido de elucidar, dirimir e dar soluções às dúvidas em questão" (Documento, denominado Declaração, de 27 de maio de 2013, assinado pelos Bispos Dom Irineu Gassen e Dom Orlando Octacilio Dotti).
Grande do Forquilha permanecerem em suas terras. ${ }^{16}$

O grau de complexidade amplia ainda mais quando se analisa a relação da Fetraf-Sul com governos do PT. Como já mencionamos, é inegável a vinculação da trajetória da federação em tela com o PT, pois o agravamento dos conflitos territoriais em regiões ocupadas por agricultores familiares intensificou-se a partir de 2004, justamente no período em que o Governo Federal foi comandado pelo PT e, no Rio Grande do Sul, no período de 2010-2014, foi governado por Tarso Genro, do mesmo partido, e que já havia sido ministro da Justiça no governo Lula.

O contexto político descrito deveria ser um facilitador para que os representantes da Fetraf-Sul tivessem facilidade e legitimidade na interlocução com os governos; contudo, a situação não se mostrou assim. Por longos anos, os referidos sindicalistas enfrentaram uma dupla dificuldade: tiveram de assimilar as críticas feitas pela base e pela sociedade quanto à 
postura dos governos do $\mathrm{PT}$ em relação à política territorial indigenista, principalmente em regiões ocupadas por agricultores familiares, simultaneamente tiveram a dificuldade de se estabelecer como interlocutores dos governos para o tema. A dificuldade de legitimidade e diálogo com os governos está relacionada a dois aspectos, primeiramente porque, da mesma forma que a Fetraf-Sul, o PT possui em seu programa a defesa do direito indígena; em seguida, pelo fato de os membros do partido e do governo não conseguirem enxergar a especificidade dos impactos da política territorial indígena nas regiões ocupadas por agricultores familiares.

Esse dilema resultou na decisão da Fetraf-Sul de fazer ações de mobilização e de enfrentamento com o governo, objetivando chamar a atenção deste para a gravidade vivida pela sua base. Alguns momentos servem de exemplificação desse enfrentamento. $\mathrm{O}$ primeiro deles é quando a FetrafSul decide ocupar o Centro Administrativo do estado do Rio Grande do $\mathrm{Sul}^{17}$, paralisando a administração e exigindo uma nova postura do governo Tarso Genro como intermediador no diálogo com o Governo Federal. Esta ação produziu efeito na medida em que, na sequência, o referido governador marcou audiências, das quais participaram representantes da FetrafSul com o Ministério da Justiça, com o Ministério da Casa Civil e com o Ministério do Desenvolvimento Agrário e o próprio governador.

Esse conjunto de audiências serviu para que o centro do governo reconhecesse que a política indigenista deveria levar em consideração a realidade específica das regiões de agricultores familiares e para a legitimação da Fetraf como interlocutora para esta temática. Nesse sentido, não houve mudança prática na implementação da referida política, resultando em uma ação no intuito de dialogar diretamente com a presidente Dilma Rousseff. Isso ocorreu quando os agricultores ocuparam o salão em Novo Hamburgo (11 de outubro de 2013), no qual a presidente faria a formatura de alunos do Pronatec (SOUZA, 2013). ${ }^{18}$ Esta ação resultou em uma audiência com Dilma Rousseff, que se comprometeu a garantir a manutenção dos
17 Esse fato aconteceu em 15 de maio de 2013. Para mais informações, ver: <www. radioaltouruguai.com.br $>$.

18 Reportagem feita pela rede Gaúcha de Rádio em: $<$ http://www.radioplanetario. com/web/index.php?menu= noticias\&id $=5112>$. 
agricultores em suas propriedades. Apesar desse compromisso, os processos administrativos de demarcação prosseguiram, levando os agricultores a bloquearem o Ministério da Justiça com cruzes e caixões representando a morte de milhares de agricultores familiares (CORREIO BRAZILIENSE, 2013) ${ }^{19}$.

19 Esta manifestação ocorreu no dia 4 de novembro de 2013 e repercutiu na imprensa nacional. Ver: <http://www. correiobraziliense.com.br/app/ noticia/cidades/2013/11/06/ interna_cidadesdf,397362/ agricultores-do-rio-grandedo-sul-protestam-contra-ademarcacao-de-terras.shtml>.

20 Essas ações de mobilização e enfrentamento foram complexas e recheadas de ações políticas e de negociações que não cabem no escopo deste texto. Um maior detalhamento delas pode ser obtido em Kujawa (2014).

21 "A Fetraf, no seu corpo de direção e lideranças, tem consciência que a sua posição é difícil de ser compreendida e que não é cômoda, pois no momento que você faz um discurso simplesmente próagricultor fica fácil. $\mathrm{Ou}$, ao contrário, faz um discurso próindígena também fica fácil, mas quando você entra defendendo que tem que resolver $\mathrm{o}$ problema dos dois, muitas vezes, causa incompreensão, tantos dos agricultores, quanto dos indígenas e da sociedade, porém temos a convicção, clareza que este de fato é o caminho" (Entrevistado 4).
Esta última ação repercutiu nacionalmente e provocou uma mudança na postura do Governo Federal, que suspendeu temporariamente os processos administrativos de demarcação de terras indígenas em áreas ocupadas por agricultores familiares e estabeleceu mesas de diálogos com cada caso específico, o que, na prática, até o presente momento, não produziu solução para nenhum caso. ${ }^{20}$

\section{Considerações finais}

Visivelmente, a Fetraf-Sul assume uma postura de autonomia e de defesa de suas bases, mesmo que isso represente, em alguns momentos, a incompreensão de outras entidades do seu campo político. Ao mesmo tempo, expressa com clareza a convicção que tem quanto ao seu posicionamento da defesa do direito territorial dos agricultores e dos indígenas. Muito embora a posição assumida pela Fetraf possa ser incômoda, difícil de ser compreendida ${ }^{21}$. A defesa unilateral dos indígenas ou dos agricultores seria mais facilmente compreendida pela sociedade e pelas partes envolvidas.

Em relação a possíveis soluções dos problemas, os dirigentes são enfáticos em afirmar que, em primeiro lugar, eles passam pelo reconhecimento do direito dos agricultores e dos indígenas: um está vivendo na terra; outro busca voltar para uma terra na qual seus antepassados viveram e que, neste caso, independentemente de quem ficar com a terra, terá um sujeito (índios ou agricultores) que ficará sem a terra que precisa para viver. Portanto, soluções que venham do Judiciário definirão o direito territorial de um grupo sem garantir o direito do outro.

Percebe-se que a luta social envolvendo esses dois sujeitos coletivos vem produzindo tensões e conflitos para além dos diretamente envolvidos na disputa pela terra; ou 
seja, essa práxis política redefine, reconfigura e produz tensões

no interior das entidades de representação dessas categoriais sociais fazendo com que haja dúvidas, desconexão histórica e ausência de legitimidade, bem como alianças e lutas comuns entre entidades que, por força de conflitos anteriores, em particular, entre sem-terra e latifundiários, no caso em questão, colocam-se no mesmo lado.

Quando o conflito pela terra não envolvia indígenas e nem comunidades quilombolas e, sim, latifúndio e pequenos agricultores (posseiros, sem-terra, arrendatários, dentre outros), havia uma definição ideológica e de representação mais definida e clara; se a luta social atual em questão não envolvesse territórios que contemplam pequenos agricultores (identificados como familiares), com titulação legal e secular e, sim, o latifúndio, possivelmente não haveria tensão e reconfiguração na esfera das mediações políticas, pois a propriedade privada da terra, aliada a fatores históricoculturais dos sujeitos envolvidos, continua sendo central na sociedade contemporânea.

Enfim, a intensa luta social que se manifesta no Sul do Brasil, em particular entre indígenas e pequenos agricultores, pós-anos 2000, pela sua especificidade, intensidade e midialização, vem fazendo com que a sociedade em geral, bem como as entidades de representação e/ou mediação política, tomem partido, definam sua posição, atuação e, se necessário for, produzam fissuras históricas e demarquem os novos e específicos sujeitos coletivos a serem representados e mediados.

\section{Referências}

BECKER, Ítala Irene Balise. O índio kaingáng no Rio Grande do Sul. São Leopoldo: Editora da Unisinos, 1995.

BRASIL. Lei $\mathrm{n}^{\circ} 11.326$, de 24 de julho de 2006. Estabelece as diretrizes para a formulação da Política Nacional da Agricultura Familiar e Empreendimentos Familiares Rurais. Diário Oficial 
da República Federativa do Brasil, Brasília, DF, 24 jul. 2006. Disponível em: <http://www.planalto.gov.br/ccivil_03/_ato20042006/2006/lei/111326.htm>. Acesso em: 22 nov. 2013.

CARINI, Joel. Estado, índios e colonos: o conflito na reserva indígena de Serrinha no norte do Rio Grande do Sul. Passo Fundo: UPF, 2005.

.Migrações compulsórias de agricultores e reterritorializações: recampesinizações no noroeste do Rio Grande do Sul. In: TEDESCO, João Carlos; CARINI, Joel João (Org.). Conflitos agrários no norte gaúcho. Passo Fundo: IMED, 2010. v. 3.

CENTRAL ÚNICA DOS TRABALHADORES. Nota pública pela preservação de direitos dos agricultores familiares, povos indígenas e quilombolas. maio 2013. Disponível em: <http://cutrs. org.br>. Acesso em: 6 abr. 2015.

CONSELHO INDIGENISTA MISSIONÁRIO. Site Oficial. [s.d.]. Disponível em: <http://www.cimi.org.br/site/pt-br/>. Acesso em: 22 nov. 2013.

CORREIO BRAZILIENSE. Agricultores do Rio Grande do Sul protestam contra a demarcação de terras. 6 nov. 2013. Disponível em: <http://www.cimi.org.br/site/pt-br/>. Acesso em: 10 nov. 2013.

FEDERAÇÃO NACIONAL DOS TRABALHADORES E TRABALHADORAS NA AGRICULTURA FAMILIAR. Site Oficial. 2001. Disponível em: <http://www.fetraf.org.br>. Acesso em: 6 abr. 2015.

FEDERAÇÃO NACIONAL DOS TRABALHADORES NA AGRICULTURA FAMILIAR DA REGIÃO SUL. Site Oficial. [s. d.]. Disponível em: <http://www.fetrafsul.org.br>. Acesso em: 6 abr. 2015.

KUJAWA, Henrique. A política territorial indígena no Rio Grande do Sul durante o século XX. In: TEDESCO, João Carlos. Conflitos Agrários no Norte do Rio Grande do Sul. Porto Alegre: Letra Vida; Passo Fundo: IMED, 2014.

. Conflitos territoriais envolvendo indígenas e agricultores no norte do Rio Grande do Sul: a trajetória de políticas públicas contraditórias. 2014. 181 f. Tese (Doutorado em Ciências Sociais) Universidade do Vale do Rio dos Sinos, São Leopoldo, 2014.

. Conflitos territoriais envolvendo indígenas eagricultores:

uma análise histórica e jurídica de políticas públicas contraditórias. Curitiba: CRV, 2015. 
LAROQUE, Luís Fernando da Silva. Lideranças Kaingang no Brasil Meridional (1808-1889). São Leopoldo: Instituto Anchietano, 2000. (Série Antropologia, n. 56).

NACKE, Anelise; BLOEMER, Neusa Maria Sen. Os kaingang no oeste catarinense: tradições e atualidade. Chapecó: Argos, 2007.

PICOLOTTO, Everton Lazzaretti. A formação de um sindicalismo de agricultores familiares no Sul do Brasil. Sociologias, Porto Alegre, v. 16, n. 35, p. 204-235, jan./abr. 2014.

RÁDIO ALTO URUGUAI. 2013. Disponível em: <www. radioaltouruguai.com.br>. Acesso em: 6 abr. 2015.

RIO GRANDE DO SUL. Assembleia Legislativa. Relatório da CPI do Índio. Porto Alegre: Assembleia Legislativa, 1968. (Mimeografado).

SOUZA, Edson. Pres Dilma Recebe Pequenos Agricultores em Novo Hamburgo. 12 out. 2013. Disponível em: <http://www. radioplanetario.com/web/index.php? $m e n u=$ noticias \&id $=5112>$. Acesso em: 1 jun. 2015.

. Relatório e conclusões do grupo de trabalho criado pelo Decreto n. 37.118/1996 para analisar questões indígenas no Rio Grande do Sul. 1997. (Mimeografado).

VEIGA, Juracilda. Estudo de Fundamentação Antropológica da área denominada Passo Grande do Forquilha, municípios de Sananduva e Cacique Doble (RS). Brasília: Funai, 2005. (Portaria no 1.136 , de 29 de setembro de 2005).

WERLANG. Alceu Antônio. Disputas e ocupações do espaço no oeste catarinense: atuação da Companhia Territorial Sul Brasil. Chapecó: Argos, 2006.

Submetido em: 20/07/2017

Aceito em: 30/07/2017 


\title{
MEDIATIONS AND REPRESENTATIONS IN CONFLICT IN THE FIGHT AGAINST THE LAND BETWEEN INDIGENOUS AND FARMERS IN NORTH OF RIO GRANDE DO SUL, BRAZIL
}

\begin{abstract}
In the last century, in the northern region of Rio Grande do Sul, dozens of new indigenous land claims were set up in places of centenarian colonization of family farmers. The conflicts arising out of this context go beyond the historically constituted binomial of the struggle between latifundi/ agribusiness versus landless/small farmers and, consequently, provoke the reconfiguration of social movements in the countryside, especially the National Federation of the Agricultural Worker's Family (Fetraf), which historically Articulated ideologically and programmatically with the indigenous causes, entities, and movements that represented them. Movements that, historically, were in the same field of struggle, are now seen in different fields. This article, using documentary sources, bibliographies and interviews, analyzes the dilemmas faced by these subjects, the way of reformulating their discursive practices and reconfiguring their actions along with their bases and in the society as a whole to take account of this new reality.
\end{abstract}

Keywords: Social Conflicts. Indigenous People. Family Farmers. Public Policy. 